Pacific Journal of Mathematics

AN EXTREMAL LENGTH CRITERION FOR THE
PARABOLICITY OF RIEMANNIAN SPACES 


\title{
AN EXTREMAL LENGTH CRITERION FOR THE PARABOLICITY OF RIEMANNIAN SPACES
}

\author{
WeLLINGTON H. Ow
}

It is the purpose of this paper to show that a given Riemannian space satisfying a regularity condition is parabolic if and only if the extremal distance of a fixed ball in the space from the ideal boundary of the space is infinite.

We will also show that the harmonic modulus of a space bounded by two sets of boundary components coincides with the extremal distance between the two sets.

\section{Statements of Main Results}

1. Regularity condition. Throughout this paper we denote by $R$ a noncompact $C^{\infty}$ Riemannian space with the ideal boundary $\beta$. We always assume that $R$ is orientable and connected. Let $A$ be the complement of a regular subregion of $R$ with the relative boundary $\alpha$. We also assume that $A-\alpha$ is connected. We consider the following regularity condition for $R$ (more precisely, for $A$ ):

For any nonconstant harmonic function $u$ defined on a region $\Omega \subset A$, the set $\{x \in \Omega|| \nabla u(x) \mid=0\}$ has zero capacity.

This condition is always satisfied if the dimension of $R$ is two. This is also true, for example, when the metric tensor $g_{i j}$ is real analytic on $A-\alpha$. A typical case is furnished by a locally flat $A-\alpha$.

In this paper we only consider those spaces $R$ for which the above regularity condition is met.

2. Extremal length. Let $\rho$ be a density, i.e. a nonnegative Borel function on $A$, and let $\Gamma$ be a family of curves $\gamma$ which issue from a point in $\alpha$ and lie in $A-\alpha$. We define the harmonic extremal length, or simply the extremal length of $\Gamma$, by

$$
\lambda(\Gamma)=\sup _{\rho \neq 0} \frac{L(\Gamma, \rho)^{2}}{V(A, \rho)},
$$

where $V(A, \rho)=\int_{A} \rho^{2} d V$ and $L(\Gamma, \rho)=\inf _{\Gamma} \int_{\gamma} \rho d s$. Here $d V$ and $d s$ are the volume and the line element

We are particularly interested in the family $\Gamma_{\beta} \subset \Gamma$ of all curves $\gamma \in \Gamma$ terminating at $\beta$.

3. Parabolicity. We call $R$ parabolic, $R \in O_{G}$, if $R$ carries no nonconstant positive superharmonic function. The main object of this 
paper is to prove:

THEOREM 1. The space $R$ is parabolic if and only if $\lambda\left(\Gamma_{3}\right)=\infty$.

4. Moduli. Let $\Omega$ be a regular subregion of $R$ with relative boundary $\beta_{\Omega} \subset A-\alpha$, and let $u_{\Omega}$ be the continuous function on $\bar{\Omega} \cap A$ which is harmonic in the interior of $\bar{\Omega} \cap A$ with $u_{\Omega} \mid=0$ and $u_{\Omega} \mid \beta_{\Omega}=1$. The constant $\mu_{\Omega}$ given by

$$
\log \mu_{\Omega}=1 / \int_{\bar{\Omega}_{\cap A}} d u_{\Omega} \wedge * d u_{\Omega}
$$

is called the harmonic modulus, or simply the modulus of $\bar{\Omega} \cap A$ with respect to $\alpha$. It is easy to see that

$$
\mu_{\Omega} \leqq \mu_{\Omega^{\prime}}
$$

for $\Omega \subset \Omega^{\prime}$. Therefore, we can define $\mu_{R}$, the harmonic modulus of $A$ with respect to $\alpha$, as the directed limit

$$
\mu_{R}=\lim _{\Omega \rightarrow R} \mu_{\Omega} .
$$

It is again easy to see that $u_{R}=\lim _{\Omega \rightarrow R} u_{\Omega}$ exists and is continuous on $A$, harmonic on $A-\alpha$ with $u_{R} \mid \alpha=0$. Moreover,

$$
\log \mu_{R}=1 / \int_{\Delta} d u_{R} \wedge * d u_{R} .
$$

It can be seen that $R \in 0_{G}$ if and only if $\mu_{R}=\infty$ (Glasner [3]). Thus Theorem 1 may be considered as a special case of

THEOREM 2. The following identity is valid:

$$
\lambda\left(\Gamma_{\beta}\right)=\log \mu_{R} .
$$

The proof will be given in 5-9.

\section{PARABOLIC CASE}

5. A general inequality. We start with proving

$$
\lambda\left(\Gamma_{\beta}\right) \geqq \log \mu_{R} \text {. }
$$

Let $\Gamma_{B_{\Omega}}$ be the family of curves $\gamma \in \Gamma$ which lie in $\bar{\Omega} \cap A$ and terminate at a point of $\beta_{\Omega}$. Define $\rho$ as $\left(\log \mu_{\Omega}\right)\left|\nabla u_{\Omega}\right|$ in the interior of $\bar{\Omega} \cap A$ and as zero elsewhere in $R$. For $\gamma \in \Gamma_{\beta_{\Omega}}$,

$$
\int_{\gamma} \rho d s=\int_{\gamma}\left(\log \mu_{\Omega}\right)\left|\nabla u_{\Omega}\right| d s \geqq\left(\log \mu_{\Omega}\right) \int_{\gamma} \frac{d h}{d s} d s=\log \mu_{\Omega} .
$$




\section{Therefore}

$$
L\left(\Gamma_{\beta_{\Omega}}, \rho\right)=\inf _{\Gamma} \int_{\gamma} \rho d s \geqq \log \mu_{\Omega} .
$$

By (2) we also obtain

$$
V(A, \rho)=\int_{\bar{\Omega} \cap A}\left(\log \mu_{\Omega}\right)^{2}\left|\nabla u_{\Omega}\right|^{2} d V=\left(\log \mu_{\Omega}\right)^{2} \int_{\bar{\Omega}_{\cap A}} d u_{\Omega} \wedge * d u_{\Omega}=\log \mu_{\Omega},
$$

and infer by (1) that

$$
\lambda\left(\Gamma_{\beta_{\Omega}}\right) \geqq \log \mu_{\Omega} .
$$

Since every $\gamma \in \Gamma_{\beta}$ contains a $\gamma^{\prime} \in \Gamma_{\beta_{\Omega}}$, we can easily see that $\lambda\left(\Gamma_{\beta}\right) \geqq \gamma\left(\Gamma_{\beta_{\Omega}}\right)$ (cf. Ahlfors-Sario [1, p. 222]). Thus (8) implies that $\lambda\left(\Gamma_{\beta}\right) \geqq \log \mu_{\Omega}$ for every $\Omega$. On letting $\Omega \rightarrow R$ we obtain (7). that

6. Now suppose that $R \in 0_{G}$. Then since $\mu_{R}=\infty$, (7) implies

$$
\lambda\left(\Gamma_{\beta}\right)=\log \mu_{R}=\infty .
$$

In order to complete the proofs of Theorems 1 and 2 , we have only to show the validity of (6) under the assumption $R \notin 0_{G}$. Note that in our discussion thus far we have not made any use of the regularity condition.

\section{HYPERBOLIC CASE}

7. $u$-lines. Hereafter we assume that $R \notin 0_{G}$. Then $u_{R}$, to be denoted simply by $u$, is not constant on $A$. Since $u \mid \alpha=0$ and $u \mid A-\alpha>0$, we infer that $|\nabla u|$ can be extended continuously to all of $A$ and that $|\nabla u| \mid \alpha \neq 0$.

For each $x \in \alpha$ we consider the unique curve $l_{x}$ issuing from $x$ and such that $l_{x}-x \subset A-\alpha, * d u=0$ on $l_{x},|\nabla u| \neq 0$ on $l_{x}$. Moreover we require that $l_{x}$ either terminates at $\beta$ or at a point of $A$ at which $|\nabla u|=0$. Such an $l_{x}$ will be called a $u$-line. As $y$ traces $l_{x}, u(y)$ increases. Thus we can classify points of $\alpha$ as follows:

$$
\begin{aligned}
& \alpha_{0}=\left\{x \in \alpha \mid \lim _{y \rightarrow \beta, y \in l_{x}} u(y)<1\right\}, \\
& \alpha_{1}=\left\{x \in \alpha \mid \lim _{y \rightarrow \beta, y \in l_{x}} u(y)=1\right\},
\end{aligned}
$$

with

$$
\alpha=\alpha_{0} \cup \alpha_{1} .
$$


8. Vanishing surface area. We denote by $d S$ the surface element of $\alpha$. We wish to show that

$$
S\left(\alpha_{0}\right)=\int_{\alpha_{0}} d S=0 .
$$

Let $F_{-1}$ be the set of points $x \in \alpha$ such that $l_{x}$ terminates at some point of $R$. Clearly $F_{-1} \subset \alpha_{0}$, and we set $F_{0}=\alpha_{0}-F_{-1}$. By the regularity condition in $\S 1$, we see that $S\left(F_{-1}\right)=0$ (cf. Brelot-Choquet [2]). Therefore we only have to show that $S\left(F_{0}\right)=0$. Let

$$
F_{n}=\left\{x \in F_{0} \mid \lim _{y \rightarrow \beta, y \in l_{x}}(1-u(y)) \geqq \frac{1}{n}\right\} \quad(n=1,2, \cdots) .
$$

Since $F_{0}=\bigcup_{1}^{\infty} F_{n}$, it is sufficient to show that $S\left(F_{n}\right)=0$.

We can find a positive harmonic function $\omega$ in the interior of $A$ with the following properties (cf. Nakai [4]): (a) $\omega$ has the boundary values 0 on $\alpha$, (b) $\lim _{y \rightarrow \beta, y \in l_{x}} \omega(y)=\infty$ for $x \in F_{0}$, (c) $\int_{A}\left|\nabla \omega_{c}\right|^{2} d V \leqq c$, with $\omega_{c}=\min (\omega, c)$ for every positive number $c$.

Fix a $c>0$ arbitrarily and a point $y_{x} \in l_{x}$ with $w_{c}\left(y_{x}\right)=c$ for each $x \in F_{n}$.

Set $v=1-u$ on A. In a neighborhood of a point in $\alpha$ with respect to $A$ we may incorporate $v$ into a coordinate system, say $v=x^{1}$, while $x^{2}, \cdots, x^{m}$ are $m-1$ linearly independent parameters for $\alpha$. Then

$$
|\Delta v|^{2}=g^{11}\left(\frac{\partial v}{\partial x^{1}}\right)^{2}=g^{11}
$$

Since $* d v=|\nabla v| d S=\sqrt{g^{11}} d S$ on $\quad \alpha, S\left(F_{n}\right)=0 \quad$ is equivalent to $\int_{F_{n}} * d v=0$. Observe that

$$
\begin{aligned}
c \int_{F_{n}} * d v & \leqq \int_{F_{n}}\left(\int_{x}^{y_{x}} \frac{\partial \omega_{c}}{\partial v} d v\right) * d v \\
& =\int_{F_{n}} \int_{x}^{y_{x}}\left|\frac{\partial \omega_{c}}{\overline{\partial v}}\right| d v \wedge * d v \\
& =\int_{F_{n}} \int_{x}^{y_{x}}\left|\frac{\partial \omega_{c}}{\partial x^{1}}\right| g^{11} d V .
\end{aligned}
$$

By the Schwarz inequality we have

$$
\int_{F_{n}} \int_{x}^{y_{x}}\left|\frac{\partial \omega_{c}}{\partial x^{1}}\right| g^{11} d V \leqq\left(\int_{F_{n}} \int_{x}^{y_{x}}\left|\frac{\partial \omega_{c}}{\partial x^{1}}\right|^{2} g^{11} d V\right)^{1 / 2}\left(\int_{F_{n}} \int_{x}^{y_{x}} g^{11} d V\right)^{1 / 2}
$$




$$
\begin{aligned}
& \leqq\left(\int_{A}\left|\nabla \omega_{c}\right|^{2} d V\right)^{1 / 2}\left(\int_{A}|\nabla v|^{2} d V\right)^{1 / 2} \\
& \leqq \sqrt{c}\left(\int_{A} d u \wedge * d u\right)^{1 / 2} .
\end{aligned}
$$

From this we infer that

$$
\left|\int_{F_{n}} * d v\right| \leqq 1 / \sqrt{\mu_{R} c} \text {. }
$$

Since the number $c$ can be arbitrarily large, we have $\int_{F_{n}} * d v=0$, and (11) follows.

9. Let $\rho$ be a density with $\rho \neq 0$ on $A$. Since

$$
d u \wedge * d u=|\nabla u| d V \text {, }
$$

we can compute

$$
\begin{aligned}
V(A, \rho) & =\int_{A} \rho^{2} d V=\int_{A} \frac{\rho^{2}}{|\nabla u|^{2}} d u \wedge * d u \\
& \geqq \int_{\alpha_{1}}\left(\int_{l_{x}} \frac{\rho^{2}}{|\nabla u|^{2}} d u\right) * d u \\
& =\int_{\alpha_{1}}\left(\int_{l_{x}} \frac{\rho^{2}}{|\nabla u|^{2}} d u \cdot \int_{l_{x}} 1^{2} d u\right) * d u \\
& \geqq \int_{\alpha_{1}}\left(\int_{l_{x}} \frac{\rho}{|\nabla u|} d u\right)^{2} * d u .
\end{aligned}
$$

On $l_{x}\left(x \in \alpha_{1}\right)$ we have $d u=|\nabla u| d s$, and thus

$$
V(A, \rho) \geqq \int_{\alpha_{1}}\left(\int_{l_{x}} \rho d s\right)^{2} * d u
$$

From $l_{x} \in \Gamma_{\beta}$ for $x \in \alpha_{1}$ we obtain $\int_{l_{x}} \rho d s \geqq L\left(\Gamma_{\beta}, \rho\right)$, and therefore

$$
V(A, \rho) \geqq L\left(\Gamma_{\beta}, \rho\right)^{2} \int_{\alpha_{1}} * d u
$$

On the other hand, by (11), we have $\int_{\alpha_{1}} * d u=\int_{\alpha} * d u$. Take an arbitrary regular region $\Omega$ with $\beta_{\Omega} \subset A-\alpha$. Then

$$
\int_{\alpha} * d u=\lim _{\Omega \rightarrow R} \int_{\alpha} * d u_{\Omega}
$$

Here we see that

$$
\int_{\alpha} * d u_{\Omega}=\int_{\beta_{\Omega}} * d u_{\Omega}=\int_{\beta_{\Omega}-\alpha} u_{\Omega} * d u_{\Omega}=\int_{\bar{\Omega} \cap A} d u_{\Omega} \wedge * d u_{\Omega},
$$


and infer that

$$
\int_{\alpha} * d u=\lim _{\Omega \rightarrow R} \int_{\bar{\Omega} \cap A} d u_{\Omega} \wedge * d u_{\Omega}=\int_{A} d u \wedge * d u .
$$

This together with (5) and (12) implies the inequality

$$
\log \mu_{R} \geqq \frac{L\left(\Gamma_{\beta}, \rho\right)^{2}}{V(A, \rho)} .
$$

Since $\rho$ was arbitrary, we now conclude that

$$
\log \mu_{R} \geqq \lambda\left(\Gamma_{\beta}\right) \text {. }
$$

We combine this with (7) and obtain (6).

The author is indebted to Professor Leo Sario, chairman of his doctoral committee, who guided his research, and also to Professor Mitsuru Nakai, with whom the author had many invaluable discussions.

\section{REFERENCES}

1. L. Ahlfors and L. Sario, Riemann Surfaces, Princeton University Press, Princeton, 1960 .

2. M. Brelot and G. Choquet, Espace et lignes de Green, Ann. Inst. Fourier Grenoble 3 (1951), 199-263.

3. M. Glasner, Harmonic functions with prescribed boundary behavior, Doctoral dissertation, University of California, Los Angeles, 1966.

4. M. Nakai, Green potential of Evans type on Royden's compactification of a Riemann surface, Nagoya Math. J. 24 (1964), 205-239.

Received January 30, 1967. This work was sponsored in part by the U. S. Army Research Office-Durham, Grant DA-AROD-31-124-G472. The results of this paper are part of the author's dissertation at the University of California, Los Angeles.

UNIVERSity of CALIFornia, Los ANGeles 


\section{PACIFIC JOURNAL OF MATHEMATICS}

\section{H. ROYDEN}

Stanford University

Stanford, California

\author{
J. P. JANS \\ University of Washington \\ Seattle, Washington 98105
}

\section{EDITORS}

\author{
J. DugundJI \\ Department of Mathematics \\ Rice University \\ Houston, Texas 77001 \\ Richard ARENS \\ University of California \\ Los Angeles, California 90024
}

\section{ASSOCIATE EDITORS}
E. F. BECKENBACH
B. H. NeumanN
F. WOLF
K. YOSIDA

\section{SUPPORTING INSTITUTIONS}

\author{
UNIVERSITY OF BRITISH COLUMBIA \\ CALIFORNIA INSTITUTE OF TECHNOLOGY \\ UNIVERSITY OF CALIFORNIA \\ MONTANA STATE UNIVERSITY \\ UNIVERSITY OF NEVADA \\ NEW MEXICO STATE UNIVERSITY \\ OREGON STATE UNIVERSITY \\ UNIVERSITY OF OREGON \\ OSAKA UNIVERSITY \\ UNIVERSITY OF SOUTHERN CALIFORNIA
}

\author{
STANFORD UNIVERSITY \\ UNIVERSITY OF TOKYO \\ UNIVERSITY OF UTAH \\ WASHINGTON STATE UNIVERSITY \\ UNIVERSITY OF WASHINGTON \\ AMERICAN MATHEMATICAL SOCIETY \\ CHEVRON RESEARCH CORPORATION \\ TRW SYSTEMS \\ NAVAL ORDNANCE TEST STATION
}

Mathematical papers intended for publication in the Pacific Journal of Mathematics should be typewritten (double spaced). The first paragraph or two must be capable of being used separately as a synopsis of the entire paper. It should not contain references to the bibliography. Manuscripts may be sent to any one of the four editors. All other communications to the editors should be addressed to the managing editor, Richard Arens at the University of California, Los Angeles, California 90024.

50 reprints per author of each article are furnished free of charge; additional copies may be obtained at cost in multiples of 50 .

The Pacific Journal of Mathematics is published monthly. Effective with Volume 16 the price per volume (3 numbers) is $\$ 8.00$; single issues, $\$ 3.00$. Special price for current issues to individual faculty members of supporting institutions and to individual members of the American Mathematical Society: $\$ 4.00$ per volume; single issues $\$ 1.50$. Back numbers are available.

Subscriptions, orders for back numbers, and changes of address should be sent to Pacific Journal of Mathematics, 103 Highland Boulevard, Berkeley 8, California.

Printed at Kokusai Bunken Insatsusha (International Academic Printing Co., Ltd.), 7-17, Fujimi 2-chome, Chiyoda-ku, Tokyo, Japan.

PUBLISHED BY PACIFIC JOURNAL OF MATHEMATICS, A NON-PROFIT CORPORATION

The Supporting Institutions listed above contribute to the cost of publication of this Journal, but they are not owners or publishers and have no responsibility for its content or policies. 


\section{Pacific Journal of Mathematics}

A. A. Aucoin, Diophantine systems ............................. 419

Charles Ballantine, Products of positive definite matrices. I ............... 427

David Wilmot Barnette, A necessary condition for d-polyhedrality ............ 435

James Clark Beidleman and Tae Kun Seo, Generalized Frattini subgroups of finite groups ......................................... 441

Carlos Jorge Do Rego Borges, A study of multivalued functions ............. 451

William Edwin Clark, Algebras of global dimension one with a finite ideal

lattice ...............................................

Richard Brian Darst, On a theorem of Nikodym with applications to weak convergence and von Neumann algebras .........................

George Wesley Day, Superatomic Boolean algebras .....................

Lawrence Fearnley, Characterization of the continuous images of all

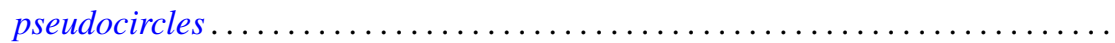

Neil Robert Gray, Unstable points in the hyperspace of connected subsets....... 515

Franklin Haimo, Polynomials in central endomorphisms .................. 521

John Sollion Hsia, Integral equivalence of vectors over local modular lattices . . . . 527

Jim Humphreys, Existence of Levi factors in certain algebraic groups .......... 543

E. Christopher Lance, Automorphisms of postliminal $C^{*}$-algebras ............ 547

Sibe Mardesic, Images of ordered compacta are locally peripherally metric . . . . 557

Albert W. Marshall, David William Walkup and Roger Jean-Baptiste Robert Wets,

Order-preserving functions: Applications to majorization and order

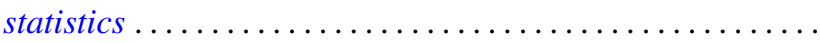

Wellington Ham Ow, An extremal length criterion for the parabolicity of

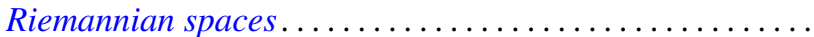

585

Wellington Ham Ow, Criteria for zero capacity of ideal boundary components of

Riemannian spaces...................................... 591

J. H. Reed, Inverse limits of indecomposable continua .................. 597

Joseph Gail Stampfli, Minimal range theorems for operators with thin spectra . . . 601

Roy Westwick, Transformations on tensor spaces..................... 613

Howard Henry Wicke, The regular open continuous images of complete metric

spaces ........................................... 621

Abraham Zaks, A note on semi-primary hereditary rings .............. 627

Thomas William Hungerford, Correction to: "A description of $\operatorname{Mult}_{i}\left(A^{1}, \cdots, A^{n}\right)$

by generators and relations" ............................. 629

Uppuluri V. Ramamohana Rao, Correction to: "On a stronger version of Wallis' formula".............................................. 629

Takesi Isiwata, Correction: "Mappings and spaces" ................... 630

Henry B. Mann, Josephine Mitchell and Lowell Schoenfeld, Correction to:

"Properties of differential forms in $n$ real variables" .... . .

James Calvert, Correction to: "An integral inequality with applications to the

Dirichlet problem"............................. 